\title{
ACERCA DE LO JUSTO, LO LEGAL Y LO LEGITIMO. Cultura política en la escuela media*
}

\author{
LUCÍA LITICHEVER ** \\ PEDRO NÚÑEZ ${ }^{* * *}$
}

\begin{abstract}
RESUMEN
El trabajo presentado pretende indagar la cultura política promovida en la escuela media. Más allá de resaltar la importancia que tiene la misma en el proceso de socialización política de los jóvenes, nos interesa analizar las ideas de justicia que se ponen en juego, así como los regímenes disciplinarios y consejos de convivencia vigentes. Para ello proponemos un análisis de las nociones de juventud y de autoridad planteadas en las normativas de los sistemas de convivencia sancionados en la Ciudad de Buenos Aires y en la Provincia de Buenos Aires. Por último presentamos el caso de una escuela media de la Ciudad de Buenos Aires, a fin de acercarnos al proceso de implementación de la nueva normativa, así como a las percepciones y formas de resolución de los conflictos. A lo largo del trabajo esperamos poder mostrar la sedimentación de una cultura escolar y una forma de pensar a los jóvenes que condicionan las actitudes en la escuela, a pesar de las modificaciones que intentan llevarse a cabo.
\end{abstract}

Palabras clave: Autoridad, Desigualdad, Cultura política

* El presente trabajo forma parte del proyecto PAV «Intersecciones entre desigualdad y educación media: un análisis de las dinámicas de producción y reproducción de la desigualdad escolar y social en cuatro jurisdicciones», dirigido por Inés Dussel, en el Área de Educación de FLACSO Argentina.

** Licenciada en Ciencias de la Educación (UBA), aspirante a Magíster en Ciencias Sociales con orientación en Educación (FLACSO) y becaria de Programa Área de Vacancia (PAV). E-Mail: litichever@flacso.org.ar.

*** Licenciado en Ciencia Política (UBA), Magíster en Estudios y Políticas de Juventud por la Universidad de Lleida y la de Barcelona. Actualmente cursa el Programa de Doctorado en Ciencias Sociales (UNGSIDES), becario de la Comisión de Investigaciones Científicas de la Provincia de Buenos Aires en cuestiones de juventud y asistente de investigación de FLACSO. E-Mail: pnunez@flacso.org.ar. 


\title{
SOBRE O JUSTO, O LEGAL E O LEGITIMO: Cultura política na escola média
}

\section{RESUMO}

Este trabalho pretende estudar a cultura política desenvolvida na escola média. Além enfatizar a importância da mesma no processo socialização política dos jovens, interessa-nos analisar as idéias de justiça que são colocadas, bem como os regimes disciplinares e os conselhos de convivência em vigor. Para isto, propomos uma análise das noções de juventude e de autoridade contempladas nas normas dos sistemas de convivência aprovadas na Cidade de Buenos Aires e na Província de Buenos Aires. Por último, apresentamos o caso de uma escola média da Cidade de Buenos Aires, a fim de nos aproximarmos do processo de aplicação da nova norma, bem como as percepções e as formas de resolução de conflitos. Ao longo do trabalho, esperamos mostrar a sedimentação de uma cultura escolar e de um modo de pensar os jovens que condicionam as atitudes na escola, apesar das modificações que tentam introduzir.

Palavras Chave: Autoridade, Desigualdade, Cultura Política.

\section{REGARDING TO WHICH IS JUST, LEGAL AND LAWFUL: Political culture in high school}

\begin{abstract}
The submitted work seeks to investigate the political culture promoted in high schools. Further to emphasize the importance of political socializing of the young, we are interested in analizing the ideas of justice that are put on for discussion as well as the disciplinary political systems and current advice for common life. For this purpose, we propose an analysis of the youth and authority notions exposed in the sanctioned common life normatives of the City of Buenos Aires and the Province of Buenos Aires. Lastly, we hereby submit the case of the high school in the City of Buenos Aires in order to get nearer to the implementation process of the new normative as well as the perceptions and ways of trouble shooting. Along the work we hope to show the settlement of a school culture and a way of thinking of the young, who impose conditions to their attitudes at school, although the modifications that are intended to be carried out.
\end{abstract}

KeY WORDS: AUTHORITY, INEQUALITY, POLITICAL CULTURE 


\section{Presentación}

LA ARGENTINA ATRAVESÓ EN la década del noventa una serie de reformas que produjeron considerables cambios en la estructura política, social y económica. Dichas transformaciones nos llevan a prestar atención a las nuevas dinámicas desiguales, más móviles y flexibles, que se suman a aquellas vinculadas a cuestiones de clase, género o de poder (Fitoussi y Rosanvallon, 1997). A su vez, las configuraciones promovidas por el capitalismo flexible, tal como Sennett (2000) ha remarcado, detrás de un discurso que enfatiza la individualización y autonomía, afectan elementos fundamentales de integridad, identidad y compromiso de los sujetos. Cambian los sentidos de pertenencia como los modos de socialización.

En este trabajo analizamos la cultura política promovida en la escuela media como una forma de comprender el proceso de socialización política de los jóvenes. Para ello nos interesa indagar las nociones de juventud y de autoridad planteadas en las normativas de los sistemas de convivencia sancionados en la Ciudad de Buenos Aires y en la Provincia de Buenos Aires. Por último presentaremos el caso de una escuela media de la Ciudad de Buenos Aires a fin de analizar el proceso de implementación de la nueva normativa, así como las percepciones y formas de resolución de los conflictos.

Entendemos por cultura política la forma en que se cristalizan relaciones de poder en constante conflicto. Partimos de la idea que las características que adopte la cultura política en cada institución influirán tanto sobre las maneras en que se perciben las desigualdades como en la producción y reproducción de las mismas. ¿Cómo perciben los diferentes actores institucionales la desigualdad? ¿Qué desigualdades están legitimadas y/o naturalizadas y cuáles activan mecanismos de reclamo? ¿Qué mecanismos de participación y reclamo existen?

La cultura política, desde una definición clásica, se expresa tanto a partir de la diversidad de praxis y de las instituciones políticas como en las creencias, ideales, normas y tradiciones que dan significado a la vida política (Bobbio, Matteucci y Pasquino, 1983). Por lo tanto el análisis de la misma implica considerar, al menos, dos dimensiones: una vinculada al aspecto institucional; la otra a los valores predominantes en la cotidianeidad.

Evitamos partir de una definición predeterminada sobre lo que sería una «buena» cultura política de acuerdo a nuestras propias maneras de ver los fenómenos sociales. Por el contrario, una de las hipóte- 
sis de investigación es que podemos encontrarnos con diferentes cultura(s) política(s), en íntima relación con la cultura política local. En cada institución existirá una forma local de la política, en tanto producción de una moral que sirve de materia prima para la estructuración de conflictos (Frederic, 2004).

\section{CAMBIOS EN LAS NORMATIVAS ¿HACIA MAYOR DEMOCRATIZACIÓN?}

Uno de los cambios de mayor impacto en la escuela media tanto de la Ciudad de Buenos Aires como en la Provincia de Buenos Aires tiene que ver la constitución de nuevos órdenes normativos. Las modificaciones en la normativa se dieron a partir de un proceso de apertura e intercambio con la sociedad. En ambos distritos se fomentó el diálogo entre diferentes sectores, lo cual implicó la realización de consultas, informes, pruebas piloto; intentando promover la participación e involucramiento de la comunidad. Estas discusiones y transformaciones en las prácticas cotidianas del sistema y en las normas de convivencia en la escuela media tienen lugar en un marco político y económico particular. Por un lado, la prevalencia de gobiernos constitucionales e instituciones democráticas brinda el escenario apropiado para avanzar en la legislación, en políticas públicas que fomenten la construcción de ciudadanía y maneras diferentes de pensar la convivencia en la escuela. La expansión del horizonte democrático genera las condiciones para un cambio en los roles y las actitudes de los diferentes actores del sistema educativo. En dicho contexto el país ratificó e incorporó en su Constitución Nacional tratados internacionales que reconocen los derechos de los niños y adolescentes y existe un avance en la institucionalización de políticas de juventud, así como en los mecanismos generales de reconocimiento de los derechos humanos. Sin embargo, más allá del avance discursivo e institucional, en la cotidianeidad se torna más compleja la exigibilidad de derechos.

Por otra parte, los cambios en el contexto socioeconómico implican límites claros ante la expansión de las desigualdades, el aumento de las dinámicas de ingreso y salida de la pobreza y fundamentalmente la extensión de la precariedad y la inestabilidad laboral como rasgo estructural del mercado de trabajo. El incremento, pero especialmente la heterogeneidad y complejización de la pobreza, que ya desde inicios de la década el país atraviesa (Murmis y Feldman, 1992), impactan en el sistema escolar. Pareciera estar claro que en 
sociedades como la argentina la extensión de desigualdades y la ampliación de la brecha de ingresos, por mencionar sólo dos cuestiones, han generado un proceso de segregación socioespacial (que entre otros fenómenos se expresa en la proliferación de barrios y escuelas privadas así como en modificaciones en las relaciones interclases o en las dificultades para los sectores populares de escapar de una existencia anclada en el barrio) que refuerza los vínculos con lo cercano, lo próximo, disminuyendo las posibilidades de intercambio y de goce común del espacio público, entendido aquél como el lugar donde es posible la convivencia con el otro extraño, sin pretender que renuncie a serlo y sin pedirle que pierda alguno de los rasgos que lo convierten en tal (Bauman, 2000). Los debates más recientes resaltan que, a la par del proceso de territorialización y de espacialización de relaciones, los individuos buscan la seguridad perdida (civil o laboral) en la comunidad, a partir de la generación de vínculos de protección en el barrio, el grupo de pertenencia o la familia. Predominan pues, formas selectivas de socialización. ${ }^{1}$ La experiencia educativa de baja intensidad (Kessler, 2004) en una institución central de la producción de ciudadanía se asemeja cada vez más a un lugar de tránsito que se percibe, no va hacia ninguna parte. En esa misma sociedad que tenía, no demasiados años atrás, al ascenso social como expectativa probable, aparecen nuevos órdenes y jerarquías (Dussel, 2003). Surgen nuevas maneras de vivir las desigualdades que llevan a que los criterios y percepciones de los sujetos cambien constantemente.

En los últimos años, se renovaron los sistemas de disciplina y de gobierno en la mayoría de las jurisdicciones del sistema educativo argentino. En Ciudad de Buenos Aires y en Provincia de Buenos Aires se decretaron nuevos sistemas disciplinarios que facultan a las escuelas a decidir sus reglamentos. En el 2001 fue aprobado en la Ciudad de Buenos Aires el Sistema Escolar de Convivencia (Ley 223 de 1999 reglamentada por el Decreto $\mathrm{N}^{\circ} 1400 / 001$ de 2001) que deroga la antigua legislación nacional de 1943 (Decreto $\mathrm{N}^{\mathrm{o}} 150.073$ ). La nueva reglamentación establece que cada escuela debe decidir sus propias Normas de Convivencia a través de un Consejo de Convivencia: un espacio de intercambio, discusión y participación integrado por autoridades, docentes, estudiantes, preceptores, padres y representantes de las asociaciones de estudiantes. Esta nueva normativa se propone,

1 Entre otros, han analizado estas cuestiones Svampa (2005), Mercklen (2005) y García Canclini (1990). 
propiciar la participación democrática de todos los sectores de la comunidad educativa, según las competencias y responsabilidades de cada uno, en la elaboración, construcción y respeto de las normas que rijan la convivencia institucional con el fin de facilitar un clima de trabajo armónico para el desarrollo de la tarea pedagógica.

Por su parte, en la Provincia de Buenos Aires entra en vigencia una nueva Resolución en el 2002 (Resolución Nº1593/02) que deroga la norma anterior de 1958 (1709/58). La normativa propicia la formación de Acuerdos Institucionales de Convivencia con el propósito de «concretar una convivencia democrática en el nivel polimodal», ${ }^{2}$ y la puesta en marcha de Consejos de Convivencia Escolar encargados de regir la convivencia en la escuela.

Ante este escenario nos interesa profundizar en las implicancias de estos cambios, tomando como punto de partida la investigación dirigida por Dussel (2004), ${ }^{3}$ recordando que se dan en paralelo a procesos sociales de exacerbación de las desigualdades y fragmentación de las experiencias educativas (Tiramonti, 2004; Dussel y Finocchio, 2003; Duschatzky, 1999; Birgin y Duschatzky, 2001) y analizando qué hace la escuela con las mismas, en qué medida las reproduce y en qué medida ella misma genera prácticas exclusoras (Dubet, 2003). Los regímenes disciplinares vienen experimentado una transición de formas disciplinarias centradas en una autoridad burocrático-legal y caracterizadas por las amonestaciones, las suspensiones y las firmas de actas, a formas de autoridad más reflexivas e individualizadas, fundadas en discursos psicopedagógicos y en la idea de contrato o negociaciones, con reglamentos de convivencia consensuados por toda la comunidad educativa, asambleas de reflexión y prácticas disciplinarias preocupadas porque la sanción repare la falta cometida. El trabajo de Erica McWilliam (1999) analiza la tendencia hacia la individualización e introduce debates acerca del lugar de la vergüenza en las san-

2 La Ley Federal de Educación, a la cual la Provincia de Buenos Aires adhirió (no así la Ciudad de Buenos Aires por lo que conserva el anterior esquema de siete años de nivel primario y entre cinco o seis, dependiendo de la modalidad, de secundario), crea un ciclo de obligatorio de nueve años de Educación General Básica (aproximadamente hasta los 14 años) y un ciclo Polimodal de tres años.

3 Investigación realizada durante el año 2003 en la que se visitaron 40 escuelas secundarias públicas de la Ciudad de Buenos Aires y se analizaron sus estatutos y normas de convivencia. Véase Dussel, 2004. 
ciones. Al mismo tiempo esta autora señala que el tránsito desde la implementación del castigo físico a mecanismos mucho más sutiles del control de la disciplina en las aulas a través de la promoción de la elección libre y responsable (aunque vigilada) y la autorregulación de los sujetos han implicado formas mucho más poderosas de gobernar - vigilar y controlar - a los estudiantes. El breve recorrido realizado nos muestra cómo la escuela media se encuentra atravesada por diferentes y complejos procesos.

\section{LA NOCIÓN DE JUVENTUD Y LA ESCUELA MEDIA: A MEDIO CAMINO ENTRE LA PREPARACIÓN PARA EL TRABAJO, EL CUIDADO Y LA RESPONSABILIDAD}

Tal como una serie de investigaciones se han encargado de demostrar el concepto de juventud aislado del contexto político y social pierde todo interés y significado (Feixa, 1998; Valenzuela Arce, 2002). En la Argentina, al igual que en otros países, las fronteras entre juventud y edad adulta se tornan difusas, con discontinuidades, tensiones y oscilaciones. Las edades tienden a extenderse, se retrasa el ingreso al mercado de trabajo, la obtención de vivienda propia o la formación de pareja estable mientras aumenta considerablemente la cobertura del sistema educativo y se masifica la difusión de estilos juveniles. Una nueva condición juvenil emerge, aunque signada por un contexto que pone en juicio la idea de ciudadano propio de la modernidad.

Vivimos una época de transición en la cual los marcos que daban contención a la vida de los individuos mutan, desdibujándose la idea de un tercero que intervenga en los conflictos. Frente al derrumbe de las viejas mitologías y los puntos de referencia establecidos que sugerían un entorno social seguro (Bauman, 2003), surge una nueva legalidad, paralela a otras, donde todo está en permanente movimiento. ¿Cómo impactan estos procesos en la escuela? Mucho se ha dicho respecto a que la misma contribuía para la formación de trabajadores, disciplinando a los sujetos, a sus cuerpos, para que aprendan a tolerar las largas jornadas de trabajo. Sennett (2000) analiza en La corrosión del carácter cómo ha cambiado la relación con el trabajo donde ya nada es a largo plazo y la fábrica no es la salida laboral más usual. Plantea que en este contexto, el mercado laboral requiere nuevas habilidades, distintas de la vieja rutina de repetición y memorización. ¿Qué implican estos cambios para el ámbito educativo? ¿Cómo se consideran en la escuela las calificaciones hoy requeridas por el mer- 
cado laboral: la flexibilidad, la facilidad de adaptación, la iniciativa propia?, ¿qué consecuencias políticas genera?

En la Argentina, tradicionalmente para amplios sectores de la población la esfera de justicia se expresaba y vinculaba en referencia a los derechos sociales (Jelín, 1996), que no igualaba a todos, pero brindaba sí garantías igualitarias de justicia. Implicaba de esta manera una construcción de la esfera de lo justo a través del acceso al trabajo, desdeñando la ciudadanía política. Pero la inestabilidad laboral resultante del ocaso de la sociedad salarial puso en cuestión el acceso a estos derechos y la estabilidad de los criterios de justicia señalados. Se modifican las expectativas de los sujetos en tanto el trabajo pasa de ser espacio de experiencia de la ley a terreno de aprendizaje de injusticias propio de lo que sucedía antes de la conquista de los derechos sociales (Kessler, 2004). El sentido de la justicia se individualiza. En cierta manera podríamos decir que nos encontramos ante el dislocamiento de la transición escuela-trabajo. La educación, que implicaba un espacio de socialización central para adquirir las capacidades del individuo moderno, hoy ante las transformaciones en el entorno pareciera perder razón de ser para muchos jóvenes. Estos cambios tienen fuertes implicancias a la hora de pensar sus representaciones y prácticas políticas, especialmente ante su supuesto desencanto político (Reguillo, 2000).

¿De qué manera pensamos a los jóvenes en el sistema educativo? ¿Cuál es la forma en que los nuevos órdenes normativos plantean las interacciones en la escuela? En este punto nos interesa indagar en las nociones de juventud implícitas en los nuevos sistemas de convivencia que prefiguran una idea sobre cómo la juventud debiera ser. Las mismas nos permiten analizar el modelo de ciudadano propuesto y fundamentalmente desentrañar la manera en que se organizan en la institución escolar las relaciones entre los sujetos, los lugares de autoridad y participación.

Tanto en la Provincia de Buenos Aires como en lo que respecta a la Ciudad de Buenos Aires, predomina un enfoque que entiende la juventud como etapa en transición sin dar cuenta de los procesos que atraviesan los jóvenes. En lo que concierne a la Provincia de Buenos Aires, la justificación de las nuevas normas se basa en un detallado diagnóstico sobre las modificaciones en el contexto donde se resalta el desencanto de los adultos respecto de las utopías pasadas. Este diagnóstico es realizado de manera descriptiva como si el área educativa fuera ajena a las dinámicas y configuraciones sociales resultantes. Expresión de la desarticulación del Estado que se dio en forma para- 
lela a la sanción de las nuevas normativas. En este sentido queda explícita la ausencia de integralidad en las políticas dirigidas a los jóvenes donde cada agencia se piensa de manera separada de las otras.

La noción de juventud en la normativa presente en la Provincia de Buenos Aires es la de adolescentes atravesando una etapa en transición. Retoma así una concepción vigente durante muchos años en las políticas de juventud que resaltaba la vinculación entre la educación y el empleo, promoviendo el acceso a determinados roles propios de los adultos. La ventaja de la misma radicaba en que, en tanto la transición se realizaba en formas distintas en diferentes clases sociales, permitía hablar de varias juventudes y no de una juventud (Martín Criado, 1993), enfatizando los aspectos desiguales de las condiciones de vida, en especial el origen social. Sin embargo con el correr de los años este tipo de abordajes ha sido cuestionado. Por un lado se señala que promovía un tipo de acercamiento adultocrático, en tanto trasladaba conductas deseadas por los adultos a jóvenes que quizás experimentaban los procesos de otra manera; pero por otra parte también es cierto que tuvieron lugar cambios de tendencia estructural que llevaron a la pérdida de linealidad educación-trabajo. A pesar que la misma normativa reconoce que «aparecen muchas dificultades objetivas y materiales en una sociedad con serios problemas de oferta laboral» insiste en preconfigurar un camino que ya no es posible, o al menos, de difícil cumplimiento en tanto se propone «fomentar en los estudiantes la adquisición de roles reservados para adultos: el trabajo, la paternidad, propiedad y autoridad; pasar de abastecidos a abastecedores, de protegidos a protectores». La normativa refuerza así estereotipos sociales al sostener una fuerte división de género donde el hombre es el proveedor y la maternidad y paternidad aparecen como el camino a seguir, imponiendo el modelo de familia nuclear como naturalización del proyecto de vida. El discurso escolar se contrapone así con sus prácticas cotidianas donde surgen otras conductas; el reconocimiento de derechos de sectores discriminados (en algunos casos sobre gays y lesbianas), o diferentes maneras de vivir sus derechos sexuales y reproductivos. En definitiva, nuevas formas de familia y diferentes imágenes sobre el futuro, en las cuales se posterga la formación de pareja estable y el nacimiento de los hijos. ${ }^{4}$ Maneras distintas de vivir, reconocerse y relacionarse. Cuestiones que al no ser consideradas, amplían

4 A pesar de estas tendencias, cabe señalar que el 13,7 \% de nacimientos en el país corresponden a madres de entre 15 y 17 años (CEPAL, 2000). 
la distancia entre las normas promovidas desde la institución escolar y las prácticas sociales.

Otro aspecto a considerar es que en dicha normativa la definición de juventud parte de un enfoque psicológico entendiéndola como etapa de construcción del propio yo. Al respecto señala que:

es una etapa de transición del desarrollo humano entre la infancia y la edad adulta. La etapa psicológica de tránsito a la adultez se caracteriza por la construcción del propio yo de una propia identidad más estable y consolidada.

Este tipo de acercamiento lleva al predomino, tal como Chaves (2004) se ha encargado de señalar, de una tendencia a enfatizar los aspectos biológicos, médicos o psicológicos que intentan explicar la juventud a partir de particularidades intrínsecas de los cuerpos. Estas representaciones terminan inmovilizando a quienes trabajan con jóvenes, obstaculizando el conocimiento del otro. Finalmente la normativa contempla al alumno como un «ciudadano en formación en gradual posesión y ejercicio de sus derechos humanos en plenitud». Es decir, que los jóvenes parecieran no ser sujetos de derecho en la escuela, sino que van allí a adquirirlos.

Por su parte la normativa vigente en la Ciudad de Buenos Aires apela antes que a la inserción laboral, a la adquisición de prácticas de participación democrática. Sin embargo, al igual que en la Provincia de Buenos Aires predomina una definición adultocrática. En uno de sus apartados se propone «posibilitar la formación de los alumnos en las prácticas de la ciudadanía democrática mediante la participación responsable en la construcción de una convivencia armónica». De esta manera, a pesar de hacerlo de forma más sutil, remarca la jerarquía de la palabra adulta. El fomento de la participación es promovida desde una definición de lo que se entiende por la misma de acuerdo a preconfiguraciones no construidas por ellos. La idea de participación responsable, así como el concepto de ciudadanía democrática no son explicitados. ¿Cuándo definir que una participación es responsable y en qué momento o por qué razón deja de serlo? En este punto quizás valga la pena pensar en formas alternativas de vivir la política y lo político, no necesariamente ligados a lo institucional. Beck (1997) ha señalado, refiriéndose desde ya a otros contextos, que los jóvenes sostienen una negación de la política desde una postura altamente política. La participación adquiere similares características volátiles a 
otros ámbitos de su vida. Lo que en muchos casos contrasta con la formalidad, la rigidez y la institucionalización de la esfera política. Esto permite pensar la política y lo político de manera amplia y no restringido a ciertos esquemas institucionales o acerca de cómo debería ser la participación. Implica también que es posible que emerjan formas de participación democrática, no coincidentes con las desarrolladas por los adultos.

Finalmente ser ciudadano para la normativa de la Ciudad es: «ser responsable, respetar los símbolos patrios (emparentando ciudadanía con nacionalidad lo que estigmatiza a los alumnos inmigrantes) y participar». Pero en ningún momento se plantea como objetivo la defensa de los derechos de los jóvenes. Esto nos deja el interrogante de si la ciudadanía es vivida de la misma manera por los adultos y por los jóvenes. El debate en torno a la ciudadanía aporta algunos elementos interesantes para discutir estas cuestiones. En su ya clásico trabajo Marshall (1998) plantea a la ciudadanía como condición otorgada a miembros plenos de una comunidad, iguales en derechos y responsabilidades. Menos atención se ha prestado desde las ciencias sociales al énfasis del autor respecto a la relación ciudadanía-desigualdad. Nos referimos a la tensión, la paradoja de la ciudadanía como principio de igualdad en una sociedad de clases y de cómo la misma provoca desigualdades. En una rediscusión sobre el término, Kymlicka y Norman (1997) resaltan que la ciudadanía se encuentra íntimamente ligada a dos esferas: los derechos individuales y a la noción de vínculo a una comunidad particular. Lo que nos recuerda la centralidad de los derechos civiles, pero también remarca la necesidad de generar un lazo de confianza, un sentimiento de pertenencia. Sin embargo, nuevamente es necesario alejarse de definiciones estrictamente normativas, entendiendo la ciudadanía como un área de conflicto y de lucha. ¿Cuáles son los grupos de afinidad que se conforman? ¿Qué percepción existe sobre el conflicto?

La escuela, en tanto espacio de encuentro, es lugar para relacionarse con otros, ver y ser visto. Una suerte de refugio donde muchas veces los jóvenes intentan decir cosas, con diferentes lenguajes, que no pueden en otros sitios. Para ellos las adscripciones identitarias implican a la vez límites, un adentro y un afuera. De alguna forma la importancia que adquiere la apariencia en tanto presentación ante los otros es la marca identitaria. En la búsqueda de visibilidad la consigna parece ser mostrarse (Cremona, 2005). Pero he aquí una paradoja: la mayor visibilización que logran en una de las pocas instituciones esta- 
tales con las que tienen contacto y que posibilita el encuentro entre diferentes, tiende a homogeneizarlos al etiquetar sus prácticas. La extensión de la utilización de conceptos como el de tribus juveniles, y su apropiación por parte de los medios masivos y algunos docentes e investigadores, se realiza desde el resaltar los atributos negativos (Sánchez, 2005; Padawer, 2004; Chaves, 2005). Una mirada de distancia, de extrañamiento, donde se señala su primitivismo, se los emparenta con la barbarie, reproduciendo una misma matriz conceptual, negadora de sus prácticas. Las expulsiones de alumnas embarazadas, las sanciones por supuestas faltas de respeto a símbolos patrios $(\mathrm{Fal}-$ coni, 2004) o por usar aros, tatuajes, un tipo particular de vestimenta o peinado, vuelven a instalar al cuerpo en lugar de lucha de significados legitimados.

Frente al temor, no menor por cierto, que el respeto de la cultura juvenil derive en demagogismo juvenil legitimando exclusiones de los valores más valiosos y complejos de la cultura adulta y universal (Tenti Fanfani, 2005), abogamos más bien por incorporar la cultura política de los jóvenes como una más dentro de las que se debaten en la escuela. Quizás el desdibujamiento de la autoridad, más allá que no imposibilita la emergencia de otras, en realidad expresa la falta de una autoridad equitativa, una referencia que actúe con sentido de la justicia reconociendo las voces discordantes.

Sin duda los cambios en la normativa de convivencia implican un notorio avance respecto a las nociones de autoridad anteriormente vigentes. Sin embargo, los nuevos marcos generan sus propios límites al definir a los estudiantes como adolescentes atravesando una etapa donde la ciudadanía está en formación. El pensarse la misma como una gradual posesión restringe el ejercicio diario. Los jóvenes pasan de ser individuos a personas insertas en una relación social donde la distribución de la palabra, los saberes, la participación y la autoridad es asimétrica.

Ante las cuestiones señaladas consideramos que el estudio de las transiciones continúa siendo una herramienta conceptual interesante en tanto definamos correctamente cuál es el punto de llegada esperado. Tal como señala Dávila (2004), podemos distinguir entre la transición considerada como movimiento y como proceso (de reproducción social) donde las trayectorias de los sujetos son algo más que historias vitales personales; son un reflejo de las estructuras y los procesos sociales. Los jóvenes de hoy en día se encuentran con una situación más insegura, donde prima la incertidumbre. Su existencia está signa- 
da por la precariedad. Frente a las transformaciones de la sociedad, la transición a la vida adulta ha dejado de ser un tipo de trayectoria lineal o concebida como de final conocido a desarrollarse de acuerdo a trayectorias laberínticas (Machado Pais, 2002), que guían su relación con los otros y con las diversas instituciones con las que entran en contacto. De esta forma las transiciones se convierten en trayectorias desestandarizadas que configuran proyectos de vida diferenciados entre los jóvenes. Múltiples destinos posibles se abren, lo que nos recuerda que los orígenes sociales siguen siendo determinantes al trazar destinos de vida diferentes (Machado Pais, 1990), pero también sobre la necesidad de reconocer la heterogeneidad de situaciones del colectivo juvenil y su diversidad de itinerarios.

\section{LA CONSTRUCCIÓN DE AUTORIDAD, ENTRE EL PATERNALISMO Y LA (AUTO)RESPONSABILIDAD}

La extensión de los Consejos de Convivencia en el ámbito de la Ciudad de Buenos Aires y la Provincia de Buenos Aires como prototipo de la expansión de ideas democráticas en la escuela, resulta un interesante punto de partida para indagar acerca de las ideas de justicia e igualdad, pero también de diferencia, disenso y conflicto (Dussel, 2003), que construyen. A fin de analizar estas cuestiones nos proponemos examinar las nociones de autoridad y jerarquía que aparecen en las normativas y la autonomía que se propone a las escuelas para diseñar sus propios reglamentos. Además, consideramos necesario tener presente que estas normativas han de sufrir reformulaciones y apropiaciones diferentes al ser puestas en marcha en las escuelas.

La nueva normativa sobre la convivencia escolar es innovadora con respecto a la anterior legislación del sistema de disciplina escolar, sobre todo porque incorpora a toda la comunidad en la consulta y elaboración del proyecto de la normativa general, al mismo tiempo incluye a los distintos actores de la comunidad educativa en el diseño de las Normas de Convivencia o de los Acuerdos Institucionales de Convivencia.

Las nuevas leyes buscan generar importantes cambios en el día a día de las escuelas, se proponen modificar los vínculos que se construyen promoviendo relaciones más democráticas. Pero estas leyes se encuentran con culturas escolares particulares con las cuales van a dialogar de diferentes maneras $y$, al igual que toda reforma o innovación, serán reapropiada por la institución sufriendo modificaciones. 
Entendemos por cultura escolar, siguiendo a Viñao (2002), el conjunto de teorías, ideas, principios, normas, pautas, rituales, inercias, hábitos y prácticas. Es decir, formas de hacer y de pensar sedimentadas a lo largo del tiempo en forma de tradiciones, regularidades y reglas del juego no cuestionadas, compartidas por sus actores, y transmitidas de generación en generación. Estas tradiciones, regularidades y reglas proporcionan estrategias para integrarse en las escuelas, para llevar a cabo las tareas cotidianas y para sobrevivir a las sucesivas reformas, reinterpretándolas y adaptándolas, desde dicha cultura, a su contexto y necesidades. Su característica es la continuidad y persistencia en el tiempo, su institucionalización y una relativa autonomía. La cultura escolar sería, en síntesis, aquello que permanece y que dura; algo que las sucesivas reformas no logran más que arañar superficialmente, que sobrevive a ellas, y que constituye un sedimento formado a lo largo del tiempo (Viñao, 2002).

La nueva normativa prevé en ambas jurisdicciones que cada escuela proponga y diseñe sus propios reglamentos tomando como base la normativa general. Esto da lugar a que cada institución tome las decisiones que crea más convenientes por sus propias características y las de su comunidad. De esta manera brinda márgenes importantes de autonomía pasando de un gobierno centralizado a uno descentralizado (Dussel, 2005), permitiendo que cada escuela delinee su propia identidad institucional. Pero simultáneamente en las mismas normativas aparecen restricciones a esa autonomía. En el caso de Ciudad de Buenos Aires, se prescriben con minucioso detalle formas de proceder esperadas para el funcionamiento del Consejo de Convivencia en el que se explicitan quiénes deben integrarlo, ${ }^{5}$ en qué proporciones, ${ }^{6}$ la forma de elección de sus miembros, ${ }^{7}$ durante cuánto tiempo deben ejercer sus mandatos, ${ }^{8}$ y qué tareas deben desarrollar. ${ }^{9}$

5 El rector, representantes de profesores, asesores pedagógicos, psicopedagogos, representantes de preceptores, representantes de alumnos, centro de estudiantes, representante de padres, madres o tutores.

6 La suma de representantes de alumnos y padres no debe superar la suma de los representantes de profesores, preceptores y asesores.

7 Los miembros integrantes del consejo escolar de convivencia deben ser elegidos por votación de sus representantes.

8 Un año para alumnos y puede extenderse a dos para padres y docentes.

9 Dictar el reglamento interno, elaborar las normas de convivencia del establecimiento educativo, hacer la difusión de las mismas, analizar y revisar anualmente las normas de convivencia, proponer sanciones ante 
Por otro lado, este mismo reglamento especifica criterios para la resolución de los conflictos:

diálogo como metodología de la identificación y resolución de los problemas de convivencia; análisis y reflexión sobre las situaciones conflictivas y sus causas y posibilidad de prevención; contextualización de las transgresiones; respeto irrestricto de la dignidad e intimidad de las personas; garantía del derecho a ser escuchado y a formular descargos; valoración del sentido pedagógico de la sanción; reconocimiento y reparación del daño u ofensa a persona y/o bien de la escuela o miembro de la comunidad educativa por parte de la persona y/o grupo responsable; garantía del derecho a la información de los alumnos posibles de sanción y a sus padres o tutores durante el proceso de decisión y una vez aplicada la sanción.

Al mismo tiempo se enumera una serie de posibles sanciones para ser aplicadas a los alumnos:

apercibimiento oral, apercibimiento escrito, realización de acciones reparatorias en beneficio de la comunidad escolar, cambio de división, cambio de turno, separación del establecimiento.

También se especifica quién puede aplicar cada sanción (las primeras dos pueden ser solicitadas y aplicadas por los preceptores y los profesores, las siguientes sólo pueden ser aplicadas por el rector).

En el reglamento de Provincia de Buenos Aires también aparece la restricción a la tan mentada autonomía al detallar los criterios que deben ser tenidos en cuenta en la redacción de las normas: «la reflexión normativa, la consulta (a la comunidad); la búsqueda y encuentro de consenso; la participación activa de todos los actores». A tal punto que brinda las pautas de estilo para la redacción de las normas:

economía (los documentos deben ser breves y precisos, sin la pretensión de regular todo), flexibilidad (se debe evitar la rigidez para poder abrirse a la adaptación y contemplar excepciones) y nivel de generalidad (deben ser lo suficientemente claras para que todos los actores sepan a qué atenerse y, al mismo tiempo, deben tener amplitud para evitar la descripción detallada de todas las conductas. Es necesaria y suficiente una descripción general pero clara de las conductas que se alientan y de aquellas que se desalientan).

las transgresiones a las normas de convivencia, elaborar estrategias de prevención de los problemas de convivencia. 
A su vez, ambas jurisdicciones establecen procedimientos de seguimiento, asesoramiento y asistencia técnica de los procesos de implementación de la nueva normativa, lo que podría generar mecanismos de control por parte del gobierno central, desdibujando quizás el margen de independencia propio de cada escuela. En Ciudad de Buenos Aires: «la Secretaría de Educación del Gobierno de la Ciudad de Buenos Aires dispondrá de asistencia técnica especializada con el fin de brindar apoyo profesional e institucional y evaluar el desarrollo integral del Sistema Escolar de Convivencia en todas las escuelas». En Provincia de Buenos Aires se especifica que se llevará a cabo la «formación de un grupo de inspectores en el asesoramiento de la problemática de la convivencia institucional».

Por otra parte, no sólo se prevé la consideración de las particularidades de cada institución en el diseño específico de sus reglamentos de convivencia, sino que además en el caso de Provincia de Buenos Aires, la normativa puntualiza que «las condiciones personales, sociales, ambientales o históricas que atañen a todos los actores institucionales en el momento de producirse una transgresión deben ser incluidas en la aplicación de las normas». Lo dicho, a la vez que reconoce la diversidad - este es un cambio sustantivo en relación a la vieja legislación que no tenía en cuenta las particularidades al momento de sancionar, más que en un aspecto cuantitativo-, legitima tratos desiguales con aquellos considerados diferentes, dejando abierta la puerta para la elaboración de criterios subjetivos y particulares ante las distintas situaciones, alejándose de la posibilidad de construir un marco común de justicia. En este sentido, Myriam Southwell (2004) señala la necesidad de establecer una regla común que emparente con un horizonte de justicia.

En los nuevos reglamentos encontramos una pretensión de democratización del espacio escolar y de las relaciones de autoridad. En Ciudad de Buenos Aires, la intención de «propiciar la participación democrática de todos los sectores de la comunidad educativa, según competencias y responsabilidades de cada uno». El Consejo de Convivencia debe, como ente colegiado que representa a todos los sectores de la comunidad, discutir y elaborar el reglamento. A la vez, como dijimos antes, la misma ley específica qué tipo de sanciones imponer y quién debe aplicarlas. Esto da lugar a que se mantengan las jerarquías: no es ya el Consejo el que sanciona, sino que se sostiene una estructura vertical, donde las sanciones más severas sólo pueden ser aplicadas por el rector, la «máxima autoridad» de la institución y no discutidas colegiadamente. 
Por otra parte, el sostenimiento de las jerarquías se hace notar en las normativas, ya que se prevén sanciones únicamente para el accionar de los alumnos. Es decir, las normas y las sanciones son previstas para ser aplicadas en los estudiantes y no en todos los actores escolares. Si bien el comportamiento del personal docente es reglamentado por el estatuto docente y otros organismos distintos del reglamento de convivencia, llama la atención que una normativa que se precia inclusiva y participativa de toda la comunidad, contemple sólo a los estudiantes como sujetos de sanción. Al mismo tiempo es pertinente notar que determinadas normas del quehacer cotidiano escolar - cumplimiento de los horarios, de las tareas, la prohibición de fumar, el uso de los espacios, etc. - sólo están previstas para el accionar de los alumnos y no de toda la comunidad.

En cuanto a la noción de autoridad, la encontramos en el reglamento de Provincia de Buenos Aires tratada en paralelo a la de asimetría, aclarando que es necesario reconocer el «carácter asimétrico de las relaciones escolares, puesto que relacionan adultos con adolescentes» y es el adulto el que tiene que sostener un rol de autoridad escolar con las responsabilidades de cuidado, orientación y contención de los adolescentes. Las responsabilidades enumeradas para los adolescentes son:

comunicación honesta, responsabilidad, compromiso y esfuerzo en las tareas como estudiantes, reparación de los errores, valoración de las diferencias, un trato respetuoso de sus pares y con los docentes y valoración del esfuerzo que la comunidad realiza para posibilitar sus estudios.

De esta manera, pese a generar espacios de diálogo, las jerarquías se mantienen firmes atribuyendo responsabilidades bien distintas para unos y para otros posicionando aquí también al adolescente como un sujeto incapaz que necesita ser conducido, orientado en su comportamiento. Con este señalamiento no estamos bregando por una horizontalización total de las relaciones, por el contrario, creemos que es importante que los docentes y otros adultos de las escuelas puedan asumir sus responsabilidades de cuidado y orientación de los jóvenes, pero a la vez, creemos que muchas de las responsabilidades asignadas a los estudiantes también podrían ser pensadas para los adultos de la escuela. Además, queremos resaltar que consideramos la necesidad de reafirmar el rol docente cuidando que no se desdibuje su lugar, pero encontrando nuevos trazos que lo definan a fin de reacomodarse a las nuevas condiciones y contextos. 
En consecuencia, por un lado aparece en la normativa un discurso del ejercicio autónomo de los estudiantes que interiorizan y reflexionan las normas - se los concibe como sujetos responsables - pero al mismo tiempo se los piensa como sujetos-del-paternalismo incapaces de autogobernarse (Dussel, 2005). Retomando aquellas reflexiones de McWilliam (1999), que señalamos en el anterior apartado, la situación de control se hace notoria si analizamos los derechos que se les atribuyen a los estudiantes en la normativa de la Provincia de Buenos Aires: «garantía del derecho a ser escuchado, a formular descargos y derecho a estar informado de las posibles sanciones». Estos derechos parecen estar más orientados a la obediencia que a la propia gestión. Quizás un cambio significativo sería plantear otros derechos vinculados con la posibilidad de generar espacios y discursos propios que incentiven a los jóvenes a emitir sus opiniones, a darle lugar a su voz, buscando construir diálogos tanto entre pares como intergeneracionales. En la ley los derechos que se proponen parecen acercarse más a la posibilidad de defenderse ante un conflicto o sanción que a la posibilidad de entablar diálogos permanentes en los que se puedan tener en cuenta sus necesidades e intereses y se promuevan espacios donde tenga lugar la iniciativa propia.

Quisiéramos detenernos un momento a reflexionar sobre las sanciones y analizarlas en relación con la normativa anterior. La nueva reglamentación abre un espacio para el diálogo y la reflexión conjunta frente al conflicto y pretende que toda sanción tenga una finalidad educativa y que guarde relación con la falta cometida, aparece con fuerza la idea que la sanción debe reparar la falta cometida. La diferencia con el parte de amonestaciones es grande, allí lo que diferenciaba una falta de otra era el número de amonestaciones asignadas, incluso, tal como lo describe Narodowski (1993), la cantidad de amonestaciones determinadas ante un mal comportamiento, aumentaba más en función de a quién se agredía — según su rol jerárquico en la institución - y no tanto por la transgresión efectuada. Este sistema de sanciones, por otra parte, tenía límites de tiempo reales: principio y fin de año, ya que la acumulación de amonestaciones caducaba a fin de año, cuando los estudiantes eran indultados. Esto generaba, según Narodowski (1993), un cierto «ahorro» y «especulación» por parte de los estudiantes que fomentaba que hacia fin de año se emitían mayor cantidad de amonestaciones. El nuevo sistema propone un trabajo más sostenido a lo largo del tiempo promoviendo un trabajo sobre la convivencia institucional a largo plazo. Por otra parte, con el régimen de 
amonestaciones, el alumno no tomaba parte en la administración del castigo, no era obligatorio informarle de su situación. A diferencia de esto, hoy se promueve el derecho del alumno a ser escuchado, a formular descargos y reflexionar sobre la falta cometida. Pero la apertura y la participación de los estudiantes para resolver los conflictos de convivencia también se ve reducida en la nueva reglamentación, dado que las sanciones ya están estipuladas en la normativa general: apercibimiento oral, apercibimiento escrito, realización de acciones reparatorias en beneficio de la comunidad escolar, cambio de división, cambio de turno, separación del establecimiento.

Otra cuestión novedosa en relación con la vieja normativa de amonestaciones es, sobre todo en el caso de Provincia de Buenos Aires, el acento que se pone en la prevención «proponiendo intervenir sobre las causas de las transgresiones, promoviendo la advertencia e invitando a la reflexión antes de proceder con sanciones mayores». Quizás aquí sería interesante reflexionar sobre qué significa la prevención. En este aspecto consideramos que no es lo mismo hablar de prevención entendiendo por ella la evitación, el ocultamiento de los conflictos donde se busca que no surjan o pensar en generar espacios de convivencia democráticos que promuevan diálogos reales que enfrenten las diferencias.

El recorrido que realizamos nos deja una serie de preguntas pendientes: ¿cómo promover una verdadera participación democrática de la comunidad? ¿De qué forma construir un espacio de convivencia que dé lugar a la inclusión de distintas voces que puedan escucharse y dialogar? Quizás uno de las cuestiones más importantes que enfrentan las sociedades actuales se encuentre vinculada, tal como Bauman se ha encargado de resaltar, a los tipos de vínculos, relaciones, lazos que construimos. Bauman, retomando a Lévi-Strauss, plantea que a lo largo de la historia humana se emplearon dos estrategias para enfrentar la otredad: la antropoémica y la antropofágica. La antropoémica consistía en "vomitar», expulsando a los otros considerados irremediablemente extraños y ajenos: prohibiendo el contacto físico, el diálogo, el intercambio social y todas las variedades de comensalidad. Hoy, las variantes extremas de la estrategia «émica» son: el encarcelamiento, la deportación y el asesinato. Las formas superiores y «refinadas» (modernizadas) de esta estrategia son la separación espacial, los guetos urbanos, el acceso selectivo a espacios y la prohibición selectiva de ocuparlos. Por su parta, la estrategia antropofágica consiste en la denominada «desalienación» de sustancias extrañas: «inge- 
rir», «devorar» cuerpos y espíritus extraños para convertirlos, por medio del metabolismo, en cuerpos y espíritus «idénticos», ya no diferenciables, al cuerpo que los ingirió. Si la primera estrategia tendía al exilio o la aniquilación de los otros; la segunda, a la suspensión o la aniquilación de su otredad (Bauman, 2000:109). ¿Se presentan estas estrategias en las escuelas?, ¿qué forma toman?, ¿quiénes las llevan adelante?, ¿quiénes son los «vomitados»?, ¿y los «ingeridos»? Bauman, además menciona los no-lugares como espacios públicos, nociviles en los que se acepta la permanencia de los extraños (como una cuestión inevitable) desde su presencia física únicamente, pero sin que se establezcan relaciones entre los sujetos. Nos preguntamos entonces, ¿qué otras lógicas de relación con los otros podemos encontrar? En este aspecto resulta interesante retomar la reflexión promovida por Chantal Mouffe (2005), quien propone un nuevo modelo para el análisis de la política democrática denominado «pluralismo agonístico», el cual toma en cuenta la importancia de las pasiones en la construcción de identidades políticas o colectivas. En este aspecto la autora cuestiona la búsqueda de consenso hacia la cual la política democrática tiende en los últimos años, apelando más bien a que «el conflicto en las sociedades democráticas no puede y no debería ser erradicado, puesto que la especificidad de la democracia moderna reside, precisamente, en el reconocimiento y la legitimación del conflicto» (Mouffe, 2005:86). En tanto la distinción nosotros/ellos es constitutiva de la política como espacio de antagonismos y prerrequisito para la formación de identidades, resulta esencial establecerla de manera tal que sea compatible con el reconocimiento del pluralismo. De esta forma «lo que la política democrática requiere es que los otros no sean vistos como enemigos a ser destruidos sino como adversarios cuyas ideas serán combatidas, incluso de modo virulento, pero cuyo derecho a defenderlas nunca será puesto en cuestión» (Mouffe, 2005:86). Agonismo en lugar de antagonismo, posibilidad de disentir en vez de uniformidad de pensamiento; adversarios con quienes compartimos una lealtad común hacia ciertos principios, pero con los cuales podemos tener interpretaciones diferentes sobre los caminos a seguir. Estas reflexiones nos brindan herramientas para el análisis de los vínculos en las escuelas.

\section{DE LA LETRA DE LA LEY AL díA A DÍA ESCOLAR}

El análisis de las leyes, si bien permite adentrarnos en el espíritu y las definiciones implícitas sobre la convivencia, deja abierto el interro- 
gante acerca de qué ocurre en las prácticas mismas, donde pueden existir reformulaciones quizás más ricas y democráticas de lo que podría pronosticarse. Por otra parte, si bien los cambios en el sistema disciplinar abre un espacio para innovaciones también implica algunas permanencias en las prácticas. En una investigación sobre los reglamentos de convivencia elaborados por las escuelas medias de la Ciudad de Buenos Aires, Dussel (2005) destaca que en los mismos se refuerza la idea de que tienen la función de controlar únicamente el comportamiento de los estudiantes. Tan sólo dos sobre una muestra de veinte incorporan un lenguaje de derechos y obligaciones, la mayoría lo reemplaza por un discurso psicológico. En definitiva, la regulación de la disciplina escolar, señala la autora, se encuentra a medio camino entre una autoridad tradicional de la palabra adulta, reinstituyendo la noción de adolescentes como menores incapaces de autonomía y otra autorreflexiva, adaptable, flexible, que fomenta la autorresponsabilidad.

¿Qué conflictos se identifican en la escuela media?, ¿cómo participan los diferentes actores ante los mismos? ¿Qué estrategias se despliegan? A fin de profundizar en el análisis quisiéramos presentar el caso de una escuela con el objetivo, tanto de rastrear el proceso de puesta en marcha de la nueva normativa, así como situarnos ante las percepciones y maneras de resolver los conflictos. Si bien dista de ser generalizable, permite reflexionar sobre las características que ha adquirido la aplicación de la nueva legislación y brinda algunos elementos interesantes para el estudio de la cultura política.

La escuela se encuentra ubicada en el Barrio de Once, a pocas cuadras de la Plaza Miserere donde se halla la estación de trenes que comunica con el oeste del Gran Buenos Aires. Esto permite que a la misma asistan tanto jóvenes del barrio como del conurbano bonaerense. Al ser una escuela técnica su matrícula está compuesta principalmente por hombres. Hacia principios de la década del noventa, desde la Secretaría de Educación se realizaron convocatorias a directivos y equipos de orientación de los colegios a fin de revisar las nociones de disciplina que se aplicaban en las escuelas medias. Comenzará un largo proceso que tendrá por objetivo tanto discutir el tema de las amonestaciones, especialmente el énfasis en lo cuantitativo, como promover la reflexión con el alumno. Las iniciativas serán percibidas como posibilidad de transformación o de cambio en la manera de resolver los conflictos. En la escuela presentada fue el equipo de orientación, conformado por dos psicólogos, el encargado de acercar estas inquietudes a la institución. Planteos que encontraron en sus inicios 
fuerte resistencia por parte de los diferentes actores de la escuela quienes decían sentirse indefensos para resolver los conflictos que se presentaban sin las amonestaciones. Uno de los psicólogos participantes, quien vivió desde el comienzo el proceso señala refiriéndose a la reacción en el establecimiento: "no me iban a prohibir hablar del tema, pero me dijeron olvídate porque acá no hay problema, no hay conflicto, que se dejen de jorobar y ya». A dichos inconvenientes se sumaba que a las convocatorias para discutir sobre el tema fueron pocos quienes se acercaron.

Hacia mediados de los noventa, en consonancia con la conformación del primer Gobierno Autónomo de la Ciudad de Buenos Aires, la Secretaría de Educación convoca nuevamente a los equipos de orientación y directivos con el objetivo que cada escuela redacte un proyecto escolar de convivencia. En esos momentos desde la Secretaría se impulsa un cambio en la denominación, donde la palabra disciplina es reemplazada por la de convivencia. Encontramos aquí la tensión descentralización-centralización que planteábamos. Por un lado se propone que cada institución elabore y discuta sus propios reglamentos a la vez que desde el gobierno del sistema se imponen determinadas discusiones, tiempos de realización, compromisos, criterios de acción, etc.

Sin embargo, en la escuela no cambiaron los niveles de receptividad por parte de los docentes, quedando el equipo de orientación como único redactor del reglamento. De hecho, recuerda uno de los participantes: «no teníamos apoyo, es decir, nos dejaban hacerlo, pero no estaba el aval, no estaba legalizado». De esta manera el primer reglamento de convivencia con el que contó esta escuela fue realizado «a puertas cerradas, después se dio a conocer y no se intercambió». Entonces, pese a la fuerte insistencia desde la normativa de una participación amplia de toda la comunidad educativa en la elaboración del reglamento, nos encontramos con casos o situaciones como la que estamos relatando, en la que termina siendo un producto de unos pocos. Las dificultades para ponerse de acuerdo en los horarios de reunión a fin de tratar juntos el proyecto y la falta de permiso para salir del aula conspiraron contra dicha posibilidad. De esta forma, la propia dinámica de la escuela, su cultura escolar con sus grillas horarias y distribuciones de los tiempos y los espacios, sus prácticas disciplinarias anquilosadas juegan en contra de la introducción de innovaciones y modificaciones de las prácticas establecidas. Sin embargo, los miembros del equipo lo atribuyen más a «una resistencia» a fin de evitar los conflictos, ya que «no se podía pensar en la existencia de un 
conflicto, entonces dejemos todo así, a ver si nos metemos con algo que implica destapar cosas que mejor las dejamos».

La escuela fue renovando anualmente su reglamento aunque sin grandes diferencias de uno a otro. Ante un determinado conflicto, el profesor pide una sanción para el alumno, quien hace su descargo en el mismo formulario. Ese formulario va a la regencia. El rector puede decidir la convocatoria al Consejo de Convivencia antes de decidir su aplicación, hecho que en la escuela no es muy frecuente, quedando en manos de la máxima autoridad de la institución la decisión. Vemos que la aplicación de la sanción tiende a convertirse cada vez más, al menos en este caso, en un proceso excesivamente burocrático. Sin embargo, más allá de una orientación específica por parte de los reglamentos sobre las maneras de actuar ante las diversas situaciones en el día a día escolar, existen mecanismos informales de resolución de los conflictos que interactúan con los reglamentos formales.

Un ejemplo de interrelación la encontramos en la manera en que la escuela enfrentó el embarazo de una alumna de segundo año.

No era la primera vez que ocurría un hecho de estas características pero sí la primera que la institución es la que asume la responsabilidad de comunicárselo a la familia. Sus padres desconocen la situación a pesar de que está en el cuarto mes de embarazo. El equipo de orientación más una docente, que si bien no es la tutora del curso tiene buena relación con los alumnos, se encuentran con la madre de la alumna en la escuela para ponerla al tanto de la situación - esto se hizo a pedido de la alumna que no se animaba a contárselo a su familia-. El equipo logra mediar en la situación y habilitan un espacio para que madre e hija conversen luego de la noticia. Mientras abrazos y lágrimas ocurren en una de las oficinas contigua, los docentes discuten sobre la conveniencia de llamar al novio de la alumna, también alumno de la escuela. Finalmente lo convocan, el joven ingresa, abraza a su novia y la madre intenta apartarlo. De todas formas los tres se abrazan y conversan. El equipo de orientación y los docentes quedan conformes con la mediación realizada, sienten que la tarea está cumplida. Se sienten aliviados ya que todo salió bien: si bien a la madre le costó digerir la noticia, pudo aflojarse, conversar con su hija. Al preguntarle al equipo de orientación sobre los padres del novio, hubo respuestas evasivas. Nadie pensó en citarlos ni en tener que realizar similar mediación.

El ejemplo nos enfrenta a diversas maneras de entender el conflicto en la escuela media. Por un lado, podemos ver que algunos estudiantes encuentran en la escuela un lugar de escucha y planteo de problemas 
personales. Por otro lado, vemos una respuesta desde la institución a la demanda de la alumna, lo que da cuenta de la contemplación de casos particulares a ser resueltos, alejándose la escuela de una estructura rígida de reglamentación. También notamos que, al no ser citadas las dos familias involucradas, se reproduce una división tradicional de los roles por género desde el momento en que las acciones se enfocan principalmente en la alumna. El caso presentado nos muestra cómo se enfrentan en el cotidiano escolar los conflictos interrelacionando los cambios en las normativas con las decisiones de los sujetos.

\section{REFLEXIONES FINALES}

En este trabajo intentamos indagar en la producción de las desigualdades en la escuela media a partir del análisis de la normativa sobre convivencia. Los cambios en la misma implican un proceso de adaptación de viejos órdenes y esquemas con predominio de la jerarquía hacia un sistema más horizontal, pero que supone un tipo de autoridad y de jóvenes que tiene fuertes connotaciones en cuanto al modelo de ciudadanos en construcción. La cultura política promovida en la escuela media, si bien incorpora un lenguaje que se adapta al contexto democrático, en muchos casos consolida la desigualdad desde una forma de pensar las relaciones sociales, la jerarquía, la distribución de espacios y de derechos y responsabilidades en la institución escolar basada en la palabra adulta.

Respecto a la noción de juventud, en ambos sistemas normativos, la mirada continúa anclada en una visión de transición a la vida adulta sin incorporar en la definición las experiencias por las que atraviesan los jóvenes. Sin embargo, existen diferencias en cuanto a su enfoque. En la Provincia de Buenos Aires se plantea un estereotipo de familia y de acceso al trabajo enfatizando una mirada psicológica. Mientras, el de la Ciudad de Buenos Aires, desde un discurso que habla de jóvenes y no de adolescentes, apunta a un tipo de participación democrática esperada. Su retórica es más sutil, pero tiene también fuertes implicancias en cuanto a los roles preconfigurados. En ambos casos se refuerzan estereotipos sociales tradicionales. En el primero de los reglamentos, al sostener una fuerte división de género donde el hombre es el proveedor y la maternidad y paternidad aparecen como el camino a seguir se impone el modelo de familia nuclear como naturalización del proyecto de vida. La filtración del discurso familista presupone un concepción orgánica de la sociedad donde no hay conflicto. En la 
escuela media van a aprender a ser buenos hijos para luego ser buenos padres: de protegidos a protectores. En el otro caso se propone fomentar un tipo de participación que muchas veces no coincide con la manera de vivir la política por parte de los jóvenes.

En cuanto al lugar de la autoridad en las escuelas notamos que es necesario seguir pensando cómo reformular esta figura para que los adultos de la escuela no transiten entre el control o el autoritarismo y el dejar librados a los alumnos a su suerte. Es importante que esta autoridad esté presente desde un lugar de ayuda, escucha, orientación, transmisión del saber. Los cambios en las normativas sobre convivencia en las escuelas deberían, más allá de introducir nuevas formas de concebir la sanción, posibilitar la generación de espacios de diálogo e intercambio entre docentes y alumnos sin desdibujar la responsabilidad de cada uno. Por ello, para el análisis de los reglamentos de convivencia nos parecía importante tener en cuenta los desarrollos teóricos de Viñao (2001 y 2002) y Tyack y Cuban, (1995) sobre la cultura escolar; es decir, las tradiciones y regulaciones institucionales sedimentadas a lo largo del tiempo (Viñao, 2001); ya que entendemos que los cambios en el sistema disciplinar también implica algunas permanencias en las prácticas. Continuidades y rupturas que nos interesaba analizar.

En el caso presentado intentamos dar cuenta del proceso de implementación de los nuevos reglamentos de convivencia prestando atención a la interrelación entre las normas y las acciones cotidianas. No queremos dejar de mencionar que éste es un análisis de la normativa general y que en la puesta en marcha del proyecto de convivencia en las escuelas, pueden ocurrir cuestiones muy interesantes, tal como hicimos referencia en el caso presentado, sobre las que es necesario profundizar a lo largo de la investigación.

Buenos Aires (ARGENTINA), DICIEMBRE 2005

RECIBIDO: DICIEMBRE 2005

ACEPTADO: DICIEMBRE 2005 


\section{REFERENCIAS BIBLIOGRÁFICAS}

Bauman, Z. (2003): Comunidad: en busca de seguridad en un mundo hostil. Madrid: Siglo XXI.

- (2000): Modernidad líquida. Buenos Aires: FCE.

BECK, U. (1997): Hijos de la libertad. México: FCE.

Birgin, A. y S. DuschatzKy (comp.) (2001): ¿Dónde está la escuela? Ensayos sobre la gestión institucional en tiempos de turbulencia. Buenos Aires: Flacso/Manantial.

Bobbio, N.; N. Matteucci y G. Pasquino (1983), Diccionario de Ciencia Política. México: Siglo XXI.

Chaves, M. (2005): «Creando estilo. Alternativos en La Plata». En SÁNCHEZ (comp.): El mundo de los jóvenes en la ciudad. Rosario: CEACU.

— (2004): «La juventud en la escuela». Cuadernillo para Capacitación. La Plata: Dirección de Psicología y Orientación Social Escolar, Dirección General de Cultura y Educación, Provincia de Buenos Aires.

Cremona, F. (2005): «La sexualidad en la trama. ¿De qué hablan los jóvenes cuando hablan de sexualidad?». En SÁNCHEZ (comp.): El mundo de los jóvenes en la ciudad. Rosario: CEACU.

DÁviLA LEÓN, O. (2004): «Adolescencia y juventud: de las nociones a los abordajes». Última Década $\mathrm{N}^{\circ} 21$. Valparaíso: Ediciones CIDPA.

Dubet, F. (2003): «A escola e a exclusão». Cadernos de Pesquisa N¹19.

DUCHATZKY, S. (1999): La escuela como frontera: reflexiones sobre la experiencia escolar de jóvenes de sectores populares. Buenos Aires: Paidós.

Dussel, I. (2005): «Sobre la dificultad de construir consensos en educación. Una mirada desde la cultura política y la cultura de gestión en las políticas educativas». I Foro latinoamericano de educación: pactos y participación. Retos de la educación actual. Buenos Aires: Fundación Santillana.

(2004): «La cultura política de las escuelas medias urbanas: la reconfiguración de la autoridad y las normas en los nuevos escenarios». Proyecto de investigación, Fundación Antorchas/Flacso, Buenos Aires.

— (2003): «La escuela y la crisis de las ilusiones». En I. Dussel y S. FINOCCHIO (editores): Enseñar hoy. Una introducción a la escuela en tiempos de crisis. Buenos Aires: FCE.

— y S. FINOCCHIO (editores) (2003): Enseñar hoy. Una introducción a la escuela en tiempos de crisis. Buenos Aires: FCE.

FALCONI, O. (2004): «Las silenciadas batallas juveniles: ¿quién está marcando el rumbo de la escuela media hoy?». Actas Electrónicas VII Congreso Argentino de Antropología Social. Córdoba.

FEIXA, C. (1999): De jóvenes, bandas y tribus. Barcelona: Ariel.

Fitoussi, J. P. y P. RosAnVALlon (1997): La nueva era de las desigualdades. Buenos Aires: Manantial. 
Frederic, S. (2004): Buenos vecinos, malos políticos. Buenos Aires: Prometeo.

GARCÍA CANCLINI, N. (1990): Culturas híbridas. Estrategias para entrar y salir de la modernidad. México: Grijalbo.

JELÍn, E. (1996): «Imágenes sociales de la justicia». En E. JELÍn (comp.): Vida cotidiana y control institucional en la Argentina de los 90. Buenos Aires: Editorial Nuevo Hacer.

KeSSLER, G. (2004): Sociología del delito amateur. Buenos Aires: Paidós.

KYMLICKA, W. y W. NORMAN (1992): «El retorno del ciudadano. Una revisión de la producción reciente en teoría de la ciudadanía». Ágora Cuaderno de Estudios Políticos $\mathrm{N}^{\mathrm{0}} 7$. Buenos Aires.

MACHADO PAIS, J. (2002): «Laberintos de vida: paro juvenil y rutas de salida». Revista de Estudios de Juventud No56. Madrid: Injuve.

_ (1990): «El futuro... ¿es de todos por igual o de unos más que otros? Culturas juveniles, ocios y estilos de vida». En J. YOUNIS (editor): $N i$ diferentes ni indiferentes: Los jóvenes en el mundo de hoy. Canarias: Gobierno de Canarias.

MARShall, T. H. (1998): Ciudadanía y clase social. Buenos Aires: Losada.

MARTín CRIADO, E. (1993): «Estrategias de juventud. Jóvenes, estudios, trabajos y clases sociales». Tesis Doctoral. Madrid: Universidad Complutense de Madrid.

MCWILliam, E. (1999): Pedagogical Pleasures. New York: Peter Lang.

Merklen, D. (2005): Pobres ciudadanos. Las clases populares en la era democrática (Argentina, 1983-2003). Buenos Aires: Editorial Gorla.

Mouffe, C. (2005): «Política y pasiones: las apuestas de la democracia». En L. ARfuCH (comp.): Pensar este tiempo. Espacios, afectos, pertenencias. Buenos Aires: Paidós.

Murmis, M. y FELDMAN, S. (1992): «La heterogeneidad social de la pobreza». En A. Minujin: Cuesta Abajo. Los nuevos pobres: efectos de la crisis en la sociedad argentina. Buenos Aires: Unicef-Losada.

NARODOWSKI, M. (1993): Especulación y castigo en la escuela secundaria. Tandil: UNCPBA.

PADAWER, A. (2004): «Nuevos esencialismos para la antropología: las bandas y tribus juveniles o la vigencia del culturalismo». Actas Electrónicas VII Congreso Argentino de Antropología Social. Córdoba.

Reguillo Cruz, R. (2000): Estrategias del desencanto. La emergencia de culturas juveniles en latinoamérica. Buenos Aires: Norma.

SÁNCHEZ, S. (2005): «Jóvenes en la esquina. Explorando los sentidos de los ámbitos grupales en contextos urbanos de pobreza». En SÁNCHEZ (comp.): El mundo de los jóvenes en la ciudad. Rosario: CEACU.

SENNETT, R. (2000): La corrosión del carácter. Barcelona: Anagrama.

SOUTHWELL, M. (2004): «La escuela y la construcción de la legitimidad». El Monitor de la Educación No2, Época V, noviembre. Buenos Aires: Ministerio de Educación, Ciencia y Tecnología de la Nación. 
Svampa, M. (2005): La sociedad excluyente. La Argentina bajo el signo del neoliberalismo. Buenos Aires: Taurus.

TENTI FANFANI, E. (2005): «Transformar el mundo... de la escuela». Revista Encrucijadas. Universidad de Buenos Aires, mayo.

TiRAMONTI, G. (comp.) (2004): La trama de la desigualdad educativa. Mutaciones recientes en la escuela media. Buenos Aires: Manantial.

TyaCK, D. y Cuban, L. (1995): Tinkering Toward Utopia. A Century of Public School Reform. Cambridge MA y London: Harvard University Press.

ValenZuela ArCe, M. (2002): «De los pachucos a los cholos. Movimientos juveniles en la frontera México-Estados Unidos». En FeIXA, Molina y ALSINET (editores): Movimientos juveniles en América Latina. Barcelona: Ariel.

VIÑAO, F. A. (2002): Sistemas educativos, culturas escolares y reformas: continuidades y cambios. Madrid: Morata. (2001): «¿Fracasan las reformas educativas? La respuesta de un historiador». Anuário 2001 da Sociedade Brasileira de História da Educaçao. Campinas. 